



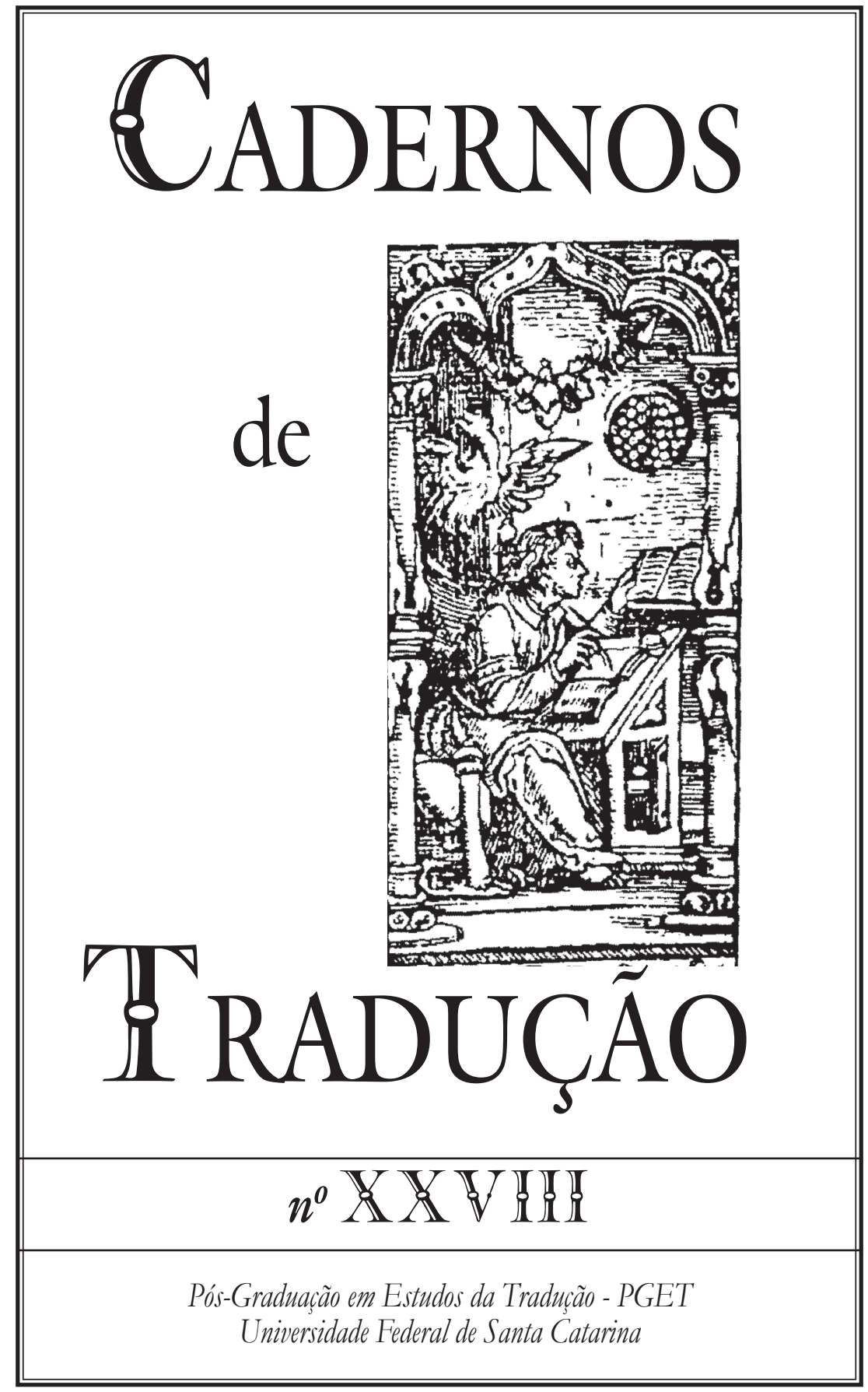




\section{Cadernos de Tradução}

№ $28-2011 / 2$

Publicação semestral da Pós-graduação em Estudos da Tradução - PGET

Universidade Federal de Santa Catarina

ISSN: $1414-526 \mathrm{X}$

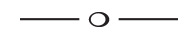

\section{Comissão Editorial}

Andréia Guerini, UFSC (Editora-Chefe) - Álvaro Faleiros, USP - Andréa Padrão, UFSC - Bruno Costa, editor e tradutor - Christiane Nord, FH Magdeburg - Claudia Borges de Faveri, UFSC - Edwin Gentzler, University of Massachusetts at Amherst - Germana Henriques Pereira, UnB - Inês Oseki-Dépré, Université de Provence - Karine Simoni, UFSC - László Scholz, Tudományegyetem Eötvös Loránd/Oberlin College - Lincoln Fernandes, UFSC - Maria Lúcia Vasconcellos, UFSC - Marie-Hélène Catherine Torres, UFSC - Markus J. Weininger, UFSC - Mauri Furlan, UFSC - Maurício Santana Dias, USP - Orlando Grossegesse, Universidade do Minho - Paulo Henriques Britto, tradutor - Roberta Barni, USP - Roberto Mulinacci, Università di Bologna - Walter Carlos Costa, UFSC - Werner Heidermann, UFSC

\section{Conselho Consultivo}

Berthold Zilly, Freie Universität Berlin - Else R. P. Vieira, University of London - Carlos Castilho Pais, Universidade Aberta de Lisboa - Francisco José Magalhães, Assoc. Portuguesa de Tradutores - Giampaolo Tonini, Università di Trieste - Heloisa Jahn, editora e tradutora - José Lambert, Katholieke Universiteit Leuven - José Roberto O’Shea, UFSC - Marcelo Jacques de Moraes, UFRJ - Márcio Seligmann-Silva, UNICAMP - Marco Lucchesi, UFRJ - Maria Paula Frota, PUC/Rio - Maria Tymoczko, University of Massachusetts at Amherst - Mark David Ridd, UnB - Michael Cronin, Dublin City University - Patricia Odber de Baubeta, University of Birmingham (UK) - Patricia Willson, Universidad de Buenos Aires/Instituto de Enseñanza Superior en Lenguas Vivas Juan Ramón Fernández - Paulo Schiller, tradutor - Pedro M. Garcez, UFRGS - Pere ComellasCasanova, Universitat de Barcelona - Samuel Titan Jr, USP - Stella Tagnin, USP - Steven F. White, St. Lawrence University - Thaís Flores Nogueira Diniz, UFMG

\section{Revisão}

Andréia Guerini, Anatália C. Corrêa, Marcelo Bueno de Paula

\section{Capa}

Dorothée de Bruchard sobre ilustração do frontispício da Bíblia traduzida para o francês por Lefèvre d'Étaples em 1530.

\section{Endereço para Correspondência}

Caixa Postal 5211 - 88040-970 - Florianópolis -SC

Tel: +55 XX 48 3721-6647 Fax: +55 XX 48 3721-9988

E-mail: andreia.guerini@gmail.com http://www.periodicos.ufsc.br/index.php/traducao 

(Catalogação na fonte pela Biblioteca da Universidade Federal de Santa Catarina)

Cadernos de Tradução / Universidade Federal de Santa Catarina. Centro de Comunicação e Expressão. Pós-graduação em Estudos da Tradução. — no 1 (1996) Florianópolis: Pós-graduação em Estudos da Tradução.

V.; $21 \mathrm{~cm}$

Semestral

ISSN: $1414-526 \mathrm{X}$

1. Universidade Federal de Santa Catarina. Centro de Comunicação e Expressão. Pós-graduação em Estudos da Tradução. 


\section{ŞUMÁRIO}

\section{Artigos}

Um tradutor é um escritor da sombra? Variações sobre a ontologia da tradução por Márcio Seligmann-Silva

In-comunicação e tradução em Walter Benjamin por Sergio Romanelli

O tradutor sob o prisma do autor: a representação do tradutor na literatura por Alessandra Matias Querido

Como forjar um arpão: uma crítica de duas traduções de Moby Dick à luz de Lacan por Nils Goran Skare

Paratexto e visibilidade na tradução de Dom Casmurro para o inglês por Luana Ferreira de Freitas

Autores polacos em tradução portuguesa (1855-2010): um levantamento preliminar por Hanna Pieta ............................ 97

A tradução francesa da linguagem compósita de Carolina Maria de Jesus por Germana Henriques Pereira de Sousa ................... 121

Cecília Meireles de epigramas en épigrammes: o ritmo como unidade de tradução por Alice Maria de Araújo Ferreira

Fushi e imortalidade: um estudo de diferença por Rodrigo Moura Lima Aragão 
Menina Acanhada: uma tradução do shïjīng por Cristiano Mahaut de Barros Barreto ................................................... 181

\section{ReSENHAS}

Virgilio Moya. La selva de la traducción. Teorías traductológicas contemporâneas (por Stella Rivello) ........................... 203

Ana Maria Garcia Bernardo. A Tradutologia Contemporânea: Tendências e Perspectivas no Espaço de Língua Alemã (por Tito Lívio Cruz Romão) ......................................... 208

Michael Oustinoff. Tradução: História, teorias e métodos (por Sinara de Oliveira Branco) ................................... 213

Ana Luna Alonso, Silvia Montero Küpper y Liliana Valado Fernández (eds). Translation Quality Assessment Policies from Galicia (por Áurea Fernández Rodríguez) ..................................... 220

Gérard Genette. Paratextos Editoriais (por Nicoletta Cherobin) ... 225

Resenhas de Traduções

La Causa Secreta y otros Cuentos de Almas Enfermas de Joaquim Maria Machado de Assis, Traducción de Juan Martín Ruiz (por Pablo Cardellino) .......................................... 233

As Aventuras de Huckleberry Finn de Mark Twain, Tradução de Rosaura Eichenberg (por Vanessa Lopes Lourenço Hanes) ... 243 


\section{ENTREVISTAS}

Entrevista com Luise Von Flotow (por Luciana Wrege Rassier e Rosvitha Friesen Blume) ........................................ 251

Entrevista com Washington Benavides (por Rosario Lázaro Igoa \& Walter Carlos Costa) .......................................... 275 
